\title{
LEXIAS REFERENTES A ESPAÇO NO PORTUGUÊS DO SÉCULO XV: EM BUSCA DE NOMES GERAIS
}

\section{WORDS REFERING TO SPACE IN $15^{\text {TH }}$ CENTURY PORTUGUESE: IN SEARCH OF GENERAL NOUNS}

\author{
Aléxia Teles Duchowny ${ }^{1}$ \\ Paola Santos Soares ${ }^{2}$
}

RESUMO: Este trabalho, um dos vários produtos do projeto "Variação e gramaticalização no sintagma nominal em línguas românicas", tem como objetivo identificar e analisar os nomes gerais do português arcaico, existentes no século XV. O corpus aqui utilizado foi um guia astrológico da primeira metade do século XV (De magia, Ms. Laud Or. 282, Bodleian Library). Não havendo conhecimento já existente sobre estas palavras de alto grau de generalização e baixo conteúdo descritivo, fez-se necessário utilizar como base, para o início da pesquisa, os poucos trabalhos sobre o tema relativos ao português brasileiro contemporâneo. Conclui-se que as lexias lugar, parte e terra, no documento analisado, já possuíam extensa capacidade de referenciação, apresentando sempre os traços [humano], [+ concreto] e [- coletivo], sem desempenhar função anafórica.

PALAVRAS-CHAVE: Nomes gerais. Português arcaico. Espaço na linguagem.

\begin{abstract}
This study is one of several products of the project "Variation and grammaticalization in the noun phrase in Romance languages". It aims to identify and analyze the general nouns of Old Portuguese from the $15^{\text {th }}$ century. The corpus used here was an astrological guide from the first half of the $15^{\text {th }}$ century (De magia, Ms. Laud Or. 282, Bodleian Library). Since there are no specific studies about words of high degree of generalization and low descriptive content, it was necessary to use as a basis, in the beginning of the research, the very few studies related to contemporary Brazilian Portuguese. It follows that the words lugar (place), parte (part) and terra (land), in the analyzed document, already presented extensive capacity of reference, always presenting the features [- human], [+ concrete] and [-collective], without playing anaphoric function.
\end{abstract}

KEYWORDS: General nouns. Old Portuguese. Space in language.

\footnotetext{
${ }^{1}$ Universidade Federal de Minas Gerais

${ }^{2}$ Universidade Federal de Minas Gerais
} 


\section{LEXIAS REFERENTES A ESPAÇO NO PORTUGUÊS DO SÉCULO XV: EM BUSCA DE NOMES GERAIS}

"Dizia Tales Filosofo, que não ha no mundo cousa mais ampla, que o lugar, porque contem em si tudo." (BLUTEAU, 1728, p. 199)

\section{INTRODUÇÃO3}

Atualmente, a palavra mais geral do léxico da língua portuguesa para se referir a espaço seria lugar, nome geral por excelência. Provavelmente área, espaço, lado, local, região, sítio, terreno, zona poderiam compor um grupo de nomes gerais, definidos como palavras semanticamente pobres e com alto grau de generalização, além da ausência de traços posicionais, direcionais e geométricos. Ao contrário de termos como atrás ou alto, não especificam a posição de seus referentes, assim como não indicam uma direção como direita ou norte, e nem dimensões como altura ou círculo (HUYGHE, 2009). Em suma, essas palavras com vastos domínios referenciais e de baixo conteúdo descritivo serão chamadas aqui de "nomes gerais de espaço".

Huyghe (2009) alerta que, se há interesse na representação linguística do espaço, as palavras citadas deveriam ser examinadas com atenção, já que permitiriam estruturar o espaço no nível mais elementar. Mas esta não é a realidade. Para o autor (cuja análise tem como objeto a língua francesa), o espaço seria um "ângulo morto", um "ponto cego" dos estudos linguísticos. Um dos motivos para esta lacuna estaria no uso terminológico da palavra lugar, conceito operatório de várias teorias e áreas do conhecimento. Como bem se sabe, o uso nocional ou metalinguístico da palavra lugar (adjunto adverbial de lugar, preposição de lugar, etc.) não tem, necessariamente, seu significado corrente.

Motivados pelos questionamentos do autor e pela existência de poucas investigações sobre o tema na língua portuguesa - como Amaral (2014a, 2014b, 2013a, b e c), Barbosa et al. (2012), Ramos (2013) -, tem-se como objetivo a identificação, a caracterização e a análise das

\footnotetext{
${ }^{3}$ Este artigo é um produto do projeto "Variação e gramaticalização no sintagma nominal em línguas românicas", em andamento na Faculdade de Letras da UFMG, sob a orientação geral do prof. Dr. Eduardo Tadeu Amaral. Agradecimentos a esse colega pelas valiosas sugestões feitas para a elaboração deste artigo. Agradecemos também ao auxiliar de pesquisa, Hugo Gonçalves Nunes (Iniciação científica voluntária).
} 
propriedades linguísticas dos nomes gerais de espaço no português arcaico. O corpus a ser analisado é um guia astrológico anônimo da primeira metade do século XV, iniciando-se, neste artigo, com o documento De magia (DUCHOWNY et al., 2014) (DM, a partir de agora). As lexias referentes a espaço encontradas neste guia astrológico em português arcaico foram campo, lugar(es), parte(s), ponto, sitos da terra, termo e terra. Parte-se da hipótese de que os nomes gerais de espaço, por fazerem referência a algo tão intrínseco à vivência e à linguagem de todo ser humano, o espaço, já existiriam em fases distantes do presente da língua portuguesa. O possível resultado desta investigação poderia oferecer pistas para um estudo dos nomes gerais ao longo do tempo e na contemporaneidade.

Para o estudo proposto, após esta introdução, será apresentado o referencial teórico adotado, seguidos de uma subseção para as lexias relativas a espaço não encontradas no corpus, outra para os termos efetivamente presentes no DM, a descrição e a análise dos dados, terminando-se com uma sucinta conclusão.

\section{ARCABOUÇO TEÓRICO}

A vivência do espaço é imprescindível a qualquer ser humano, independentemente de sua cultura. Para o ser humano existir, é preciso que ele se situe fisicamente no mundo. É por isso que Lakoff e Johnson (2003) afirmam que os conceitos relacionados à interação do humano com o ambiente físico são "concepts we live by in the most fundamental way" (p. 57). Os mesmos autores garantem que a categorização também é uma maneira primária, básica, de compreensão do mundo para os humanos e que as propriedades que caracterizam o conceito humano de objeto são interacionais. Por exemplo, quando chamamos algo de "assento" (chair), é porque o objeto tem semelhança suficiente com o protótipo elaborado para assento.

Para Halliday e Hasan (1976), na fronteira entre coesão gramatical e lexical, encontra-se a função coesiva da classe de nome geral. Um nome geral é um caso limítrofe entre um item lexical (membro de uma classe aberta) e um item gramatical (membro de um sistema fechado). A classe dos nomes gerais é um pequeno conjunto de substantivos com referência generalizada dentro de grandes classes de substantivos, tais como "substantivo humano", "substantivo de lugar", "substantivo de fatos", e similares. Exemplos (traduzidos do inglês): Gente/povo, pessoa, homem, mulher, criança, menino, menina (humano); Criatura (não humano animado); Coisa, objeto (inanimado concreto contável); Negócio (stuff) (inanimado concreto não contável); Negócio, questão (inanimado, abstrato); Movimento (ação); Lugar (lugar); Questão, ideia (fato).

De um ponto de vista lexical, os nomes gerais são membros superordenados dos conjuntos maiores lexicais, e consequentemente seu uso coesivo é uma instância do princípio geral no qual um item superordenado opera anaforicamente como um tipo de sinônimo. Os autores acima citados propõem, então, uma escala de reiteração em que todos os seus componentes são coesivos, mas os nomes gerais apresentam o nível máximo de generalidade, havendo vários níveis intermediários entre o item em si em um nome geral:

Mesma palavra/repetição - Sinônimo ou quase - Superordenado - Nome geral

$$
\text { - geral + geral }
$$

Os nomes gerais são muito usados como força coesiva, e estão no limite entre itens lexicais e substitutos/referências, mas são pouco estudados. Limitados numericamente, os autores alertam que é difícil compilar uma lista definitiva deles, porque não há uma linha bem definida entre vocabulário e gramática. Entretanto, Mahlberg (2005) afirma que seu uso é frequente. 
Apesar de não empregarem o termo "nome geral", Camacho, Dall'Aglio-Hattnher e Gonçalves (2014) também abordam a problemática da referencialidade. Para eles, os substantivos podem apresentar diferentes graus de referencialidade, situados em um contínuo cujos polos seriam a referencialidade nula e a genérica. Assim, “[...] à medida que o significado de um substantivo se especifica cada vez mais, ele não pode ser tomado como referente de um nome mais genérico. [...] Por uma questão de lógica, um termo mais genérico pode retomar um termo mais específico. O contrário causa certa estranheza na manutenção do significado da sentença” (p. 29).

\section{MÉTODO}

Não foi encontrada nenhuma investigação referente aos nomes gerais no português arcaico, para tomá-la como base. Assim, com o intuito de identificar os possíveis nomes gerais de espaço no DM, utilizou-se, principalmente Huyghe (2009) que trata do francês contemporâneo (palavras como lieu, espace, endroit). Também consultou-se o glossário de Duchowny (2014) e identificaram-se as palavras referentes a espaço ${ }^{4}$.

Em seguida, foram organizados, nas seções 3 e 4 a seguir, em dois grupos: (i) os termos buscados porém não encontrados - área, espaço, lado, linde, local, paragem, região, sítio, termo, terreno, território, zona - e (ii) os efetivamente encontrados - campo, lugar, parte, ponto, sitos da terra, termo e terra. Para todos, foram pesquisadas sua etimologia e sua significação na época ou em data a mais próxima possível do século XV. As lexias foram investigadas em González (2014) (DDGM a partir de agora), em Cunha (2006) (VPM), Cunha (2001) e Bluteau (1728). Silva (1789) e Pinto (1832) apenas foram consultados quando a lexia não foi encontrada em Bluteau (1728), a mais antiga entre as três últimas obras. Quando pertinente, exemplos foram selecionados das ocorrências encontradas.

Também verificou-se se a proposta de Mihatsch (2006 apud Amaral (2013b)) poderia ser aplicada nas lexias encontradas. Conforme a autora, os nomes gerais "constituem uma classe pequena de substantivos cuja definição é composta apenas por traços semânticos muito genéricos, tais como [+/- humano] ou [+/- contável]." (p. 170)

A pesquisa referente aos termos não encontrados e aos termos encontrados, mas que não são nomes gerais justifica-se: como não existem, ainda, parâmetros para a identificação de nomes gerais do português arcaico, é preciso, no momento, identificá-los por exclusão.

\section{CARACTERIZAÇÃO E ANÁLISE DOS DADOS}

A seguir, as lexias buscadas no corpus, com separação entre as inexistentes e as encontradas no documento.

\subsection{LEXIAS REFERENTES A ESPAÇO NÃO ENCONTRADAS NO DM}

No De magia, os termos a seguir, além de seus cognatos e afins, foram procurados, hipotetizando-se que poderiam ser nomes gerais de espaço. No entanto, como já dito na

\footnotetext{
${ }^{4}$ Agradecimentos à profa. Jânia Ramos pelas sugestões feitas oralmente no Encontro "Categorias nominais: novos estudos", em novembro de 2013, na Faculdade de Letras da UFMG.

${ }^{5}$ Devido ao espaço de mais de 500 anos entre o português contemporâneo e o do corpus, preferiu-se não analisar a animacidade dos termos, por temor de um olhar anacrônico.
} 
Metodologia, não foram encontrados. Abaixo, são indicados os testemunhos dos termos, nos casos existentes, encontrados por outros autores.

\section{(i) Área}

O DDGM, o VPM, Cunha (2001) e Bluteau (1728) indicam a presença da palavra no português arcaico. Entretanto, no DM, foi encontrada somente a palavra ayral, relativa a ar.

(ii) Canto

O DDGM, o VPM, Cunha (2001) e Bluteau (1728) indicam a presença da palavra no português arcaico.

\section{(iii) Espaço}

Há apenas uma ocorrência do adjetivo espaçoso no DM: <e o que nacer enel [o signo de Virgem] sera de coraçon espaçoso e casto e leal> (7r.18) (os negritos dos exemplos são sempre grifos nossos; número do fólio, lado do fólio, linha em que se encontra a palavra em questão). O DDGM, o VPM, Cunha (2001) e Bluteau (1728) indicam a presença da palavra no português arcaico.

(iv) Lado

O DDGM, o VPM, Cunha (2001) e Bluteau (1728) indicam a presença da palavra no português arcaico.

\section{(v) Linde}

Não foi encontrado no corpus e tampouco no VPM ou no DDGM. Cunha (2001) o situa em 1831, e alerta que o "vocábulo, contudo, deve ser do português medieval [...]" (p. 475). Silva (1789, p. 127) define linda como "linde, raia que divide os campos".

\section{(vi) Local}

A palavra local, cognatos e afins não foram encontrados no DM, no VPM e nem no DDGM, apesar de Cunha (2001) afirmar que local < locālis existe documentado desde o século XV. Bluteau (1728, p. 171) define o termo.

\section{(vii) Paragem}

A palavra paragem (parar < părāre), cognatos e afins não foram encontrados no DM e nem no VPM. O DDGM, Cunha (2001) e Bluteau (1728) indicam a presença da palavra no português arcaico.

\section{(viii) Região}

A palavra região < regīo -ōnis, cognatos e afins não foram encontrados no DM e nem no DDGM. O VPM, Cunha (2001) e Bluteau (1728) indicam a presença da palavra no português arcaico.

\section{(ix) Sítio}

De origem incerta para Cunha (2001), vem do latim situs -us. Entretanto, no DM, encontrou-se sito e não se pode afirmar com certeza se esta palavra faria parte do campo semântico de sítio ou de situar < latim tardio situāre, palavras atuais cujas formas seriam semelhantes a sito e que poderiam caber no contexto. O VPM encontrou apenas uma ocorrência do substantivo sytio, no século XV e Bluteau (1728) também indica a presença da palavra no português arcaico. 


\section{(xi) Situação}

Para Cunha (2001), a primeira ocorrência da palavra tem atestação apenas no início do século XIX, o que contradiz Bluteau (1728, p. 665), século XVIII. O termo inexiste no DDGM e o VPM não encontra ocorrências da palavra em si, mas nove delas da palavra situado.

\section{(xii) Terreno}

Tem-se apenas duas ocorrências do adjetivo térreo no DM, com o sentido de terrestre, ligado ao elemento terra (em oposição a fogo, ar e água): "[O signo de Touro] e terreo e feminino [...]" (6r.29) e "os signos terreos son recebedores de obra e perdedosos [...]" (79r.26). O DDGM, o VPM, Cunha (2001) e Bluteau (1728) indica a presença da palavra no português arcaico.

\section{(xiii) Território}

Apesar de não ter sido encontrado no DM, o DDGM atesta formas da palavra. O VPM indica uma ocorrência no século XIV e Bluteau (1728) indica a presença da palavra no português arcaico.

\section{(xiv) Zona}

A lexia zona < latim zōna também não foi encontrada pelo VPM. O DDGM indica apenas uma ocorrência no século XVI. Conforme Cunha (2001), o substantivo teria atestação na língua portuguesa ainda no século XIV. Bluteau (1728) também indica a presença da palavra no português arcaico.

A seguir, as lexias encontradas no DM. O fato de elas existirem no corpus não é suficiente para indicar se seriam nomes gerais. Assim, faz-se necessária uma análise de cada uma delas.

\subsection{LEXIAS REFERENTES A ESPAÇO ENCONTRADAS NO DM}

Abaixo, a descrição das lexias encontradas no DM, de acordo com o contexto no qual se situam.

\section{(i) Campo}

Do latim campus $-\bar{l}$, foram encontradas 51 ocorrências de campo, a partir do século XIII, pelo VPM, data em que Cunha (2001) insere a primeira ocorrência do termo. O DDGM encontra a lexia com várias acepções: "campo", "planície", "campo de batalha", "batalha campal", "campo de armas". Conforme Bluteau (1728, p. 86), as acepções são variadas: pedaço de terra cultivada; campo lavrado, mas ainda não semeado; terra fora da cidade e do povoado; sítio que ocupa o corpo do exército; o lugar em que se deu ou que se dá uma batalha; todo o exército em campanha; matéria larga para o discurso ("no sentido figurado", segundo o próprio autor, p. 98); ocasião para uma pessoa mostrar que sabe.

No DM, foram encontradas apenas as três seguintes ocorrências, todas elas [humano], [+concreto] e [-coletivo]:

(1) dise ariçtotel [...] e e feminina e nocturna seu logar e os canpos e as entradas das casas (14r.1)

(2) E a casa quarta adebda os supulturas e os canpos e os afundamentos e os cimentos e os edificios (15v.17)

(3) E a casa dozea [...] adebda canpos e selßas e bestas feras e bestas (17r.27) 
A baixa ocorrência do termo gera dificuldades para se tirar conclusões mais assertivas, contradizendo, ademais, a hipótese de Mahlberg (2005) de que os nomes gerais são de uso frequente. Dos três exemplos existentes, todos no plural e complemento de verbo, os contextos permitem abstração do termo e grande abrangência de significados, havendo potencial para já serem ou se tornarem nomes gerais. Entretanto, a lexia em si, de acordo com todos os dicionários consultados, apresenta uma gama tão variada de sentidos que não há como afirmar que sejam nomes gerais de espaço.

\section{(ii) Lugar}

O DDGM afirma que lugar < latim locālis significava, no galego medieval, "sítio, espaço, lugar, porção determinada do espaço"; "aldeia, população pequena, casal"; "classe, hierarquia, qualidade, estirpe, categoria social; "vez"; "razão, sazão", "caso, ocasião"; "povoação, local habitado"; "aqui e acolá"; "posto, emprego"; "convento, monastério". O VPM indica várias ocorrências do vocábulo no século XV. Para Cunha (2001), lugar já se encontra documentado no século XIII. Bluteau (1728) dedica seis colunas ao verbete e inicia definindo a lexia como o espaço em que se situa um corpo natural, ou a superfície que o cerca; vez; passo, sentença e alguma pequena parte de um autor; tempo para fazer alguma coisa; dignidade, preferência, estimação; força, vigor, poder, efeito; motivo; povoação pequena.

Foram encontradas, no DM, onze ocorrências de logar e 28 de logares, todas substantivos masculinos [-humano], [+concreto] e [-coletivo].

No singular, seis das ocorrências se encontram na locução prepositiva de logar a logar, como se vê no exemplo abaixo, em que não há um referente e cuja função sintática da estrutura é a de adjunto adverbial:

(4) saturno en a casa terceyra adebda discordia entre os irmaaos e antre os cabildos e antre os conpanhoes e antre os propencos e antre os creligos e remobe os sacretos e mete mal querença antre os irmaaos e aßoricia e adebda mudamentos de logar a logar (26v.20)

Nas outras oito ocorrências de logar, sete não apresentam referente e estão sempre seguidas de algum tipo de complemento (que quisermos..., mais alongado..., de escola..., apartado..., de castelo..., de seus caimentos...). Um exemplo:

(5) e se a lua for em maao logar de seus caimentos adebda cousa minguada ou cousa pequena $(81 \mathrm{v} .3)$

A ocorrência que difere das demais tem logar antecedido por um pronome possesivo (seu), este último com um referente presente no texto (lua), e seguido pelo verbo de ligação ser:

(6) dise ariçtotel lua [...] e feminina e nocturna seu logar e os canpos e as entradas das cas $<\mathrm{a}>\mathrm{s}(14 \mathrm{r} .1)$

No plural, em relação à referenciação, das 28 ocorrências, dezenove não apresentam referente, como se vê abaixo: 
(7) capicornio adebda [...] sobre os montes e as seras e os logares altos e os ermos e os gaados cabronos e os montes e as bestas feras e etreo e feminino e necturno e meridional e sua color negra (8r.1)

Cinco ocorrências estão antecedidas pelo pronome possessivo seus, o qual tem logares como referente. Exemplo:

(8) dise ariçtoteleç mercurios $\mathrm{i}_{\mathrm{i}}$ este prodenus escritorius entremediator con gotator letriateos e tremidator loctoreos - seus $\mathrm{s}_{\mathrm{i}}$ logares son as escolas e os cabidos e os logares en que se ajuntan os omees a mercar ou a conselhos : sua parte e setretion sua color e cardia (13v.1)

Finalmente, quatro ocorrências têm o termo logares como referente. Exemplo:

(9) mares este maligunus [...] seus logares ${ }_{i}$ son os caminhos e os logares li $_{i}$ onde nacen fogo $\cdot$ e as carnicerias e as pescaderias e as fererias e ou labran as armas e ou ßazan as sangres (12r.30)

Verificou-se, também, que nenhuma das 39 ocorrências é usada como elemento anafórico e apenas dezesseis delas estão antecedidas de artigo definido.

\section{(iii) Parte}

Segundo o DDGM, o substantivo parte, do latim pars părť̌s, tinha, no galego medieval, várias significações: parte, parcela, partícula, seção; lado, sítio, lugar; cada uma das pessoas que têm participação em um mesmo negócio; cada um dos litigantes de um pleito, cada um dos exércitos, partidos ou seitas que lutam; porção, fração, quantidade; direção, região, paragem; talento, habilidade; opinião, conceito; cada um dos elementos de um conjunto considerados por separado; cada uma das pessoas que participam em um mesmo assunto. $\mathrm{O}$ mesmo dicionário indica a documentação de parte em textos administrativos portugueses desde 1192, apesar de Cunha (2001) afirmar que a palavra passou a existir somente a partir do século XIII. No século XV, o VPM encontrou 64 ocorrências do termo tanto no singular quanto no plural. Bluteau (1728), que dedica dez colunas à palavra, afirma que parte é a porção do todo, dividido ou divisível; porção, quinhão; adversário, contrário em algum negócio. No plural, partes, há mais significados: talento natural, qualidades pessoais, prendas da natureza, qualquer habilidade; obrigação, ofício; partido.

No DM, o termo parte apresentou 164 ocorrências, 133 ocorrências no singular e as demais 31 ocorrências no plural. Exemplos:

(10) quero fazer este lißro sete partes $\cdots$ ena parte primeyra trotarey quantos son os ceos (1v.20)

(11) estes 12 signos cada un adebda sobre as partes do corpo do omen (8v.5)

Entre as ocorrências analisadas, a acepção do nome parte, na maioria dos contextos, é de parcela, significado etimológico. Neste sentido, o nome parte era utilizado, principalmente, para se referir a espaço físico, tanto para extensões vastas como para extensões menores. Desta forma, geralmente, apresentou os traços: [- humano], [+ concreto] e [- coletivo].

Também foram verificados os elementos que antecediam o item parte em cada caso, apresentados aqui em ordem decrescente : preposição (52 ocs.), sem antecedente ( 24 ocs.), artigo definido ( 22 ocs.), pronome indefinido e pronome possessivo (15 ocs. cada), adjetivo e numeral (9ocs. cada) e artigo indefinido ( 9 ocs.). 
Em relação aos contextos em que parte desempenharia funções características de nomes gerais, 12 casos no singular e um no plural, são compostos pelo adjetivo $m a(a)(s)$ e parte(s):

(12) as pranetas amigas con seu boon espeyto dano con onra e con folgura e con probeyto maguera que o deen de maa parte (76r.2)

(13) mays os boos espeytos das pranetas inimigas adebdan beyn de maas partes con quebantos ou com maleficios (77v.1)

Neste exemplo, "parcela", o sentido que é primeiro associado a parte, não é central para a compreensão da sentença, pois é no adjetivo que se amparam as deduções sobre o referente de maa parte. Em outras palavras, um fator que contribui para o emprego de parte neste contexto é o seu alto grau de genericidade, ou seja, o item parte foi empregado para englobar qualquer entidade que possa ser considerada má. Em resumo, levando-se em conta o número elevado de ocorrências e o esvaziamento semântico, parte já apresenta, no século XV, propriedades de nome geral.

\section{(iii) Ponto}

Conforme o DDGM, a palavra ponto significava "ocasião", "ponto", "momento, hora, instante", "signo", "estado, condição", além de fazer parte em locuções do tipo en ponto que ("tão logo", conjunção), nen ponto ("de modo algum"). Para Cunha (2001), já existiria desde o século XIII na língua portuguesa. Merece ser citada a tentativa (?) de definição de "ponto matemático" de Bluteau (1728, p. 601): ponto indivisível, que não tem parte nenhuma, nenhuma largura nem altura nenhuma, e melhor se conhece pelo que não é (!). Também é o estado de qualquer coisa.

Foram encontradas apenas sete ocorrências da palavra ponto < latim pūnctum $-\bar{l}$ no corpus, sendo que quatro delas se encontram na expressão ponto por ponto. Exemplo:

(14) e os espeytos das pranetas que son ponto por ponto fazen adebdamentos mui rezos e de grandes epresoes (52v.23)

As três outras ocorrências não apresentam referente, havendo duas antecedidas por artigo definido e uma sem antecedente algum. Exemplo:

(15) e quaaes pranetas na espeyto con elas ou quaaes son esses espeytos boos ou maaos disai cataras o senhor do acedente do ponto da conjunçon ou en qual casa esta el (45v.29).

Havendo uma quantidade tão pequena de ocorrências, há dificuldade em identificar ponto como um nome geral.

\section{(v) Sitos (da terra)}

O DDGM indica sito como um adjetivo, que significa "situado", "encontrado". O DRAE também segue uma direção semelhante, ao indicar que sito < latim situs, particípio de siněre, "deixar", é um adjetivo com o sentido de "situado" ou "fundado". |Já o VPM encontrou nove ocorrências de situado. A palavra sítio não existe no DDGM e sito é um adjetivo, "situado". Bluteau (1728) indica que sitio tem o sentido de cerco, lugar disposição, aptidão e sito significa assentado, em relação a uma terra, cidade, vila ou qualquer edifício; situado. 
No DM, foram encontradas cinco ocorrências da palavra sitos, sempre no plural, antecedidas pelo artigo definido singular os, e sempre integrante da expressão sitos da terra. Um exemplo:

(16) e outro si pos virtudes diversas enas medidas e enas partes dos sitos da terra e enas contas das partes e por ende e a teer mentes quaes partes da esfera oytaba acaecen sobre os sitos da terra enas oras que demandades saber os adebdamentos das pranetas e das outras estrelas (19r.26)

Ao se observar os exemplos, sito é sempre um substantivo ligado ao substantivo terra, seguido pela preposição da. Seu número de ocorrências é limitado e se encontra em um único contexto rígido, não favorecendo a sua análise como um nome geral.

\section{(vi) Termo}

O VPM indica 45 ocorrências da palavra, a partir do século XIV. O DDGM, como no VPM, aponta variadas grafias da palavra, todas com o sentido de "término". Bluteau (1728, pp. 114-117), já citado, também indica outras acepções para a lexia: fim e limite das ações ou das coisas em demasia; distrito ou espaço de terra aonde chega a jurisdição da justiça; modo; estado; de que principia ou acaba qualquer ação; limite ou marco.

Foram encontradas 20 ocorrências de termio(s) > latim termǐnus $-i$ "limite, fim, extremidade". Entretanto, os contextos parecem indicar de que se trata de terminologia do campo da astrologia. Segundo Page (2006), termo são divisões de tamanho variado associadas com um dos quatro elementos: terra, fogo, ar e água. Já Bluteau $(1728$, p. 116) assegura que são certos graus e limites dentro dos quais a razão e a experiência têm alcançado, em que os planetas têm a maior força. Exemplo do corpus:

(17) e as $\mathrm{pr}<\mathrm{a}>$ netas que adeßdan riquezas e ßalentias e poderios son as que estan en suas dinidades ou en termios das fortun $<\mathrm{a}>\mathrm{s}(84 \mathrm{r} .12)$

\section{(vii) Terra}

O VPM aponta várias ocorrências de terra(s) no século XV e uma de terro, enquanto Bluteau (1728) afirma que terra pode significar planeta; região, certo espaço de terra; chão, campo; terra lavrada, mas ainda não semeada; terra baldia, não lavrada, inculta; pátria, lugar de nascimento; os homens, o mundo.

No DM, foram encontradas 120 ocorrências da palavra terra < latim terram $-\bar{\imath}$. Dessas ocorrências, 114 estão no singular (tera, tyera) e seis no plural (teras). Do total de ocorrências, 39 delas fazem referência a "planeta", 38 a "solo", 11 a "elemento" (a definição é usada, aqui, em oposição aos elementos água, fogo e ar), 11 a "pátria, "país", 5 a "propriedade". Nenhum deles pode ser entendido como nomes gerais, devido às especificidades de seus significados. Entretanto, há sete ocorrências que apresentam vasto domínio referencial e baixo conteúdo descritivo, podendo ser consideradas como um nome geral cujo substituto poderia ser "lugar", e com os traços [- humano], [+ concreto] e [coletivo]. Os casos são os seguintes:

(18) e dos outros espeytos das pranetas enos tenporaes de cada tenpo do ano $\cdot \mathrm{e}$ das tenpestas e das pranetas en cada ano e en cada tera $\cdot$ e enas rebolaçoes dos reis (2r.5)

(19) os indianos por que son en tera orental e arenosa e non se leßantan dela bafos espesos poden veer de cada dia mais crara menteas estrelas pequeninas que non nos (8v.28) 
(20) e osol ena terceyra casa adebda caminhos de tera en tera e sacrificios e idelotias (29r.8)

(21) e osol ena terceyra casa adebda caminhos de tera en tera e sacrificios e idelotias (29r.8)

(22) a lua ena nobia casa adebda pelegrinaçoes de tera en tera e caminhos e preytos e lhorar e ser vencido e se for en casa de mercurio adebda siença de estrologia (31r.13)

(23) a lua ena nobia casa adebda pelegrinaçoes de tera en tera e caminhos e preytos e lhorar e ser

vencido e se for en casa de mercurio adebda siença de estrologia (31r.13)

(24) e se foren ena casa nobia adebdan avença de preto ou ganança de viagen ou andar con đonas ou casamento en tyera alhea ou achegamento a molher de outra tera (41r.3)

Nenhum deles é antecedido por artigo, já que cinco têm uma preposição como antecedente e dois um pronome indefinido.

\section{CONSIDERAÇÕES FINAIS}

Em relação às lexias inexistentes no corpus, não é possível afirmar se eram ou não nomes gerais, tendo-se apenas o DM como corpus. É necessário, então, aumentar e diversificar o corpus, na tentativa de se encontrar os termos - ou outros mais - em outros documentos, não só dentro do próprio século XV mas também nos séculos seguintes. Essa investigação foge dos objetivos deste trabalho, mas deverá ser feita posteriormente.

Em relação às lexias inexistentes no corpus, é possível inferir que lugar, parte e terra, no português arcaico, já possuíam ampla capacidade de referenciação, apresentavam sempre os traços [- humano], [+ concreto] e [- coletivo] e não executavam função anafórica. Conforme Halliday e Hasan (1976), a coesão depende não da presença de itens explicitamente anafóricos, mas do estabelecimento de uma relação semântica que pode tomar várias formas. Isto é, lugar, parte e terra já desempenham o papel de nomes gerais. Seria recomendável, no futuro, explorar melhor a participação dessas lexias na construção da coesão textual.

\section{REFERÊNCIAS}

AMARAL, Eduardo T. D. Os nomes gerais em três localidades mineiras: Campanha, Minas Novas e Paracatu. Todas as Letras, São Paulo, v. 15, n. 1, p. 138-151, 2013a. Disponível em: $<$ http://editorarevistas.mackenzie.br/index.php/t1/article/view/4083/4072>. Acesso em: 15 jan. 2015.

AMARAL, Eduardo T. D. Os nomes gerais no ordenamento jurídico brasileiro. Fórum Linguístico, Florianópolis, v. 10, n. 3, p. 170-181, 2013b. Disponível em: < https://periodicos.ufsc.br/index.php/forum/article/view/1984-8412.2013v10n3p170>. Acesso em: 15 jan. 215.

AMARAL, Eduardo T. D. A referência a outras pessoas por meio de nomes gerais em dados de língua oral. (Con)textos linguísticos, Vitória, v. 7, n. 9, p. 42-60, 2013c. Disponível em: < http://www.periodicos.ufes.br/contextoslinguisticos/article/view/4884>.

Acesso em: 15 jan. 2015. 
AMARAL, Eduardo T. D. Análise de um nome geral na fala dos mineiros: para que serve esse trem? Revista Trama, Marechal Cândido Rondon, v. 10, n. 20, p. 27-43, 2014a. Disponível em: < http://e-revista.unioeste.br/index.php/trama/article/view/9486>. Acesso em: 1 jan. 2015.

AMARAL, Eduardo T.; RAMOS, Jânia M. Nomes gerais no português brasileiro. Belo Horizonte: Fale/UFMG, 2014b. (no prelo)

BARBOSA, Eva A. et al. Negócio como nome geral no falar de Minas Gerais. Crátilo, Patos de Minas, v. 5, n. 2, p. 180-198, 2012.

http://cratilo.unipam.edu.br/documents/32405/41762/negocio.pdf

Acesso em: 15 jan. 2015.

BLUTEAU, Raphael. Vocabulario portuguez \& latino. Coimbra: Collegio das Artes da Companhia de Jesus, 1728. Disponível em:

$<$ http://www.brasiliana.usp.br/dicionario/edicao/1>. Acesso em: 7 dez. 2014.

CAMACHO, Roberto G.; DALL'AGLIO-HATTNHER, Marize M.; GONÇALVES Sebastião C. O substantivo. In: ILARI, R. (org.) Palavras de classe aberta. São Paulo: Contexto, 2014. p. 13-63.

CUNHA, Antônio G. da. Dicionário etimológico da língua portuguesa. Rio de Janeiro: Nova Fronteira, 2001.

CUNHA, Antônio G. da. Vocabulário histórico-cronológico do português medieval. Rio de Janeiro: Casa de Rui Barbosa, 2006.

DUCHOWNY, Aléxia T. et al. (Eds.). De magia (Ms. Laud Or. 282, Bodleian Library): edição e glossário. Disponível em: <http://www.nehilp.org/arquivosdonehilp/>. Acesso em: 8 dez. 2014.

GONZÁLEZ SEOANE, Ernesto (Coord.). Dicionario de dicionarios do galego medieval; corpus lexicográfico medieval da lingua galega. Disponível em:

$<$ http://sli.uvigo.es/DDGM/index.html $>$. Acesso em: 24 nov. 2014.

DRAE. Diccionario de la lengua española. Disponível em: $<$ http://rae.es/>. Acesso em: 24 nov. 2014.

HALLIDAY, M. A. K.; HASAN, R. Cohesion in English. London: Longman, 1976.

HUYGHE, Richard. Les noms généraux d'espace em français. Bruxelles: De Boeck, 2009.

LAKOFF, George; JOHNSON, Mark. Metaphors we live by. Chicago: The University of Chicago Press, 2003.

MIHATSCH, Wiltrud. Kognitive gundlagen lexikalischer hierarchien: untersucht am Beispeil des Französischen und Spanischen. Tübingen: Max Niemeyer, 2006 apud Amaral (2013a).

MAHLBERG, Michaela. English general nouns. Amsterdam/Philadelphia: John Benjamins, 2005. 
PAGE, Sophie. Astrology in medieval manuscripts. London: The British Library, 2006.

PINTO, Luiz Maria. Diccionario da Lingua Brasileira. Ouro Preto: Typographia de Silva, 1832. Disponível em: <http://www.brasiliana.usp.br/dicionario/edicao/3>. Acesso em: 24 nov. 2014.

RAMOS, Jânia. O surgimento de um nome geral: a lexia 'trem'. In: RAMOS, Jânia; COELHO, Sueli M. (Orgs.). Português brasileiro dialetal: temas gramaticais. Campinas: Mercado de Letras, 2013, p. 137-147.

SILVA, Antônio. Diccionario da lingua portugueza. Lisboa: Typographia Lacerdina, 1789. Disponível em: $<$ http://www.brasiliana.usp.br/dicionario/edicao/2>. Acesso em: 24 nov. 2014.

VITERBO, Joaquim. Elucidario das palavras, termos e frases que em Portugal antigamente se usaram e que hoje regularmente se ignoram. Lisboa: A. J. Fernandes Lopes, 1815. Disponível em: <http://purl.pt/13944>. Acesso em: 8 dez. 2014. 